\title{
A secondary analysis examining the concordance of self-perception of weight and actual measurement of body fat percentage: The CRONICAS Cohort Study
}

Anthony L. Bui ${ }^{1}$, Miguel G. Moscoso ${ }^{2,6}$, Antonio Bernabe-Ortiz ${ }^{2,3,5^{*}}$ (D), William Checkley ${ }^{4}$, Robert H. Gilman ${ }^{4}$, Liam Smeeth ${ }^{5}$ and J. Jaime Miranda ${ }^{2,6}$

\begin{abstract}
Background: Individuals' self-perceptions of weight often differ from objective measurements of body fat. This study aimed to 1) measure agreement between self-perceptions of weight and objective measurement of body fat by bioelectric impedance analysis (BIA) among Peruvian adults; and 2) quantify the association between body fat and a) baseline self-perceptions of weight and b) whether a participant underestimated their weight status.

Methods: Longitudinal data from the CRONICAS Cohort Study of 3181 Peruvian adults aged 35-years and older were used. BIA measurements of body fat were categorized across four nominal descriptions: low weight, normal, overweight, and obese. Kappa statistics were estimated to compare BIA measurements with baseline self-perceptions of weight. To quantify the association between body fat over time with both baseline self-perceptions of weight and underestimation of weight status, random effects models, controlling for socioeconomic and demographic covariates, were employed.

Results: Of the 3181 participants, 1111 (34.9\%) were overweight and 649 (20.4\%) were obese at baseline. Agreement between self-perceived and BIA weight status was found among $43.1 \%$ of participants, while $49.9 \%$ underestimated and $6.9 \%$ overestimated their weight status. Weighted kappa statistics ranged from 0.20 to 0.31 across settings, suggesting poor agreement. Compared to perceiving oneself as normal, perceiving oneself as underweight, overweight, or obese was associated with $-4.1(p<0.001),+5.2(p<0.001)$, and $+8.1(p<0.001)$ body fat percentage points, respectively. Underestimating one's weight status was associated with having $2.4(p<0.001)$ body fat percentage points more than those not underestimating only after adjusting for demographic and socioeconomic covariates.

Conclusions: Half of study participants were overweight or obese. There was poor agreement between self-perceptions of weight with BIA measurements of body fat, indicating that individuals often believe they weigh less than they actually do. Underestimating one's weight status was associated with having more body fat percentage points, but was only statistically significant after adjusting for demographic and socioeconomic characteristics. Further research should be conducted to investigate how self-perceptions of weight can support clinical and public health interventions to curb the obesity epidemic.
\end{abstract}

Keywords: Obesity, Weight self-perceptions, Chronic disease, Peru

\footnotetext{
* Correspondence: antonio.bernabe@upch.pe

${ }^{2}$ CRONICAS Centre of Excellence in Chronic Diseases, Universidad Peruana

Cayetano Heredia, Av. Armendáriz 497, Miraflores, Lima 18, Peru

${ }^{3}$ School of Public Health and Administration, Universidad Peruana Cayetano

Heredia, Lima, Peru

Full list of author information is available at the end of the article
}

(c) The Author(s). 2019 Open Access This article is distributed under the terms of the Creative Commons Attribution 4.0 International License (http://creativecommons.org/licenses/by/4.0/), which permits unrestricted use, distribution, and reproduction in any medium, provided you give appropriate credit to the original author(s) and the source, provide a link to the Creative Commons license, and indicate if changes were made. The Creative Commons Public Domain Dedication waiver (http://creativecommons.org/publicdomain/zero/1.0/) applies to the data made available in this article, unless otherwise stated. 


\section{Background}

The prevalence of overweight and obesity is rising globally $[1,2]$. Better understanding of behavioral factors that may influence obesity, such as an individual's selfperception of his or her weight, is necessary to address the current obesity epidemic. Poor self-perception of weight is associated with psychological stress [3], body image issues [4], and risk factors for poor health including poor diet, smoking, and alcohol consumption [5]. Through these mechanisms, self-perception of weight likely influences an individual's health, and, in particular, objective measurement of his or her weight. For example, self-perception of weight may influence lifestyle factors that can result in changes in body fat over time. It has been found that adults who have correctly assessed that they are overweight may practice healthier dietary habits [6]. Exploring how self-perceptions of weight relate to reality may help frame the way clinicians and public health leaders think about interventions to curb obesity.

Many studies have analyzed the association between self-perceptions of weight and body mass index (BMI) and have found varying agreement or predictability between these two measurements [7-13]. One of the limitations of BMI is its inability to differentiate lean and fat body mass [14]. Percent body fat assessed by bioelectric impedance (BIA), has been found to be a strong and effective measurement of body fat [15]. Since many studies of self-perceptions of weight are crosssectional, our understanding of the relationship between self-perceptions and objective measurements of body composition over time is limited [10-13]. Given that weight and body composition are not static, longitudinal data provide an opportunity to assess individuals' variations in body fat prospectively over time.

This study had three objectives. First, the study aimed to measure agreement between participants' self-perceptions of weight and weight status as defined by BIA-measured body fat percentage points in a cohort of Peruvian adults living in both urban and rural settings. The second objective was to quantify the association between body fat over time and baseline self-perceptions of weight. The final objective was to quantify the association between body fat over time and whether or not a participant underestimated his or her baseline weight status.

\section{Methods}

\section{Data source}

This secondary analysis employed data from the CRONICAS Cohort Study, a longitudinal data series that measured indicators related to cardiovascular health. The data includes both clinical measurements, such as bioelectric impedance analysis, as well as self-reported information obtained by questionnaires [16]. The CRONICAS
Cohort Study included Peruvian adults living in four regions that varied in urbanicity and altitude: highly urbanized Lima (at sea level), urban and rural Puno (at $3825 \mathrm{~m}$ above sea level), and semi-urban Tumbes (at sea level) [16]. Participants of the cohort were 35-years-old or older and were able to provide consent. This analysis utilized enrollment and baseline data from the CRONICAS Cohort, which were collected in September 2010. This study also utilized data from the first two follow-up visits, which occurred an average of 15 and 30 months after participants' baseline visit [16].

\section{Variables}

\section{Body fat and body mass index}

The outcome variable of this study is body fat percentage points assessed by BIA. In the CRONICAS Cohort Study, BIA measurements were taken using a TBF-300A body composition analyzer (TANITA Corporation, Tokyo, Japan) using the manufacturer's specifications. The device measures the subject's body composition, including water and fat by transmitting an electrical signal through the subject, enabling it to measure resistance, or impedance, once the signal interacts with fat tissue. This impedance metric is used to calculate body composition measurements via preprogrammed proprietary Tanita equations. The device with its corresponding equations have been used and validated in other studies showing that BIA is a strong predictor of body fat [17-21]. Measurements of body fat percentage points and weight were reported from the body composition analyzer and were recorded at baseline and at two subsequent follow-up visits. All subjects were barefoot and wore light clothing when measurements were taken [16]. Clinical assessments of subjects occurred at baseline. Height measurements were taken utilizing standardized techniques. BMI data were calculated using height and weight [16].

\section{Self-perceptions of weight}

Weight status is categorized into four nominal groups: "low weight," "normal," "overweight," and "obese." The CRONICAS Cohort Study utilized a baseline questionnaire that asked participants to self-assess their weight and select one of the four weight categories that they thought best represented their weight at that time, providing baseline data for self-perception of weight. The questionnaire was developed through the World Health Organization's (WHO's) STEP approach to survey non-communicable disease [16]. Participants were not given explanations about the descriptions of the different weight categories, and they were not able to see their actual weight at baseline. They were only notified about their measurements after finishing their survey. Further information regarding the CRONICAS questionnaire can be found in the original study protocol [16]. 


\section{Weight status definition}

Both BIA measurements of body fat percentage points and BMI are numeric, continuous variables. For this analysis, both BIA measurements and BMI were categorized into the four nominal descriptions of weight status described above. BIA measurements of body fat percentage points at baseline were categorized into the four descriptive groups based on sex, age, and ethnic groupspecific definitions using Gallagher's classification [22], which uses BMI to predict and define body fat cut-off points, an approach employed in previous studies [23-25]. For males aged 35-39years, having a maximum of $8 \%$ body fat was categorized as underweight, having at least $21 \%$ but less than $26 \%$ was categorized as overweight, and having at least $26 \%$ was categorized as obese. Those between $8 \%$ and $21 \%$ body fat were categorized as normal. For the following age and sex groups, the cutoffs between underweight and normal, normal and overweight, and overweight and obese were as follows: for females 3539 years: 21,33 , and 39 ; for males $40-59$ years: 11,23 , and 29; for females $40-59$ years: 23,35 , and 41 ; for males 60 years and older: 13, 25, and 31; for females 60 years and older: 25, 38, and 43. Because the Gallagher's classification did not have specifications for individuals age 80 years and above, it was assumed that this age group had the same definitions as the age 60 to 79 group, as was done in a previous study [23]. BMI were categorized into the four groups using standard definitions [26].

\section{Underestimation of weight status}

A binary variable indicating whether or not a participant underestimated his or her weight status was created by comparing self-perceptions of weight and BIA-defined weight categories. Participants who had a self-perceived weight category that was lower than their BIA-defined category were considered to have underestimated. In contrast, those who had a self-perceived weight category that was the same or higher than their BIA-defined category were not considered to have underestimated.

\section{Time}

The data in this study reports age in years, rounded to the nearest tenth of a year. Age was calculated by subtracting a participant's visit date from his or her birth date, allowing for greater precision of the age variable across baseline and subsequent follow-up visits.

\section{Socioeconomic status, sex, and education}

Socioeconomic status was determined using a wealth index taken from the CRONICAS Cohort Study. The wealth index was derived from survey questions regarding possession of assets (e.g., radio, TV, and internet) and household facilities (e.g., water source, floor material, and fuel use), and then split into three evenly ranked groups (low, medium, and high) [16]. Income was not used to determine socioeconomic status. This method has been employed in epidemiological studies in other low- and middle-income countries [27]. Sex was self-reported by each participant. Education level was also obtained from a self-reported questionnaire, in which participants reported the highest number of years of education that they had obtained. Education was then categorized into three groups: less than 7 years, seven to 11 years, and 12 or more years of education.

\section{Data analysis \\ Measuring agreement}

Two methods were used to compare BIA measurements of body fat to baseline self-perceptions of weight status. First, percentage agreement between these two metrics was calculated across all samples and then by setting. Second, both unweighted and weighted kappa statistics were estimated across all samples and then by setting. Confidence intervals at the 95th percentile were estimated using a bootstrap methodology of 1000 replications. Using the kappa statistic has been substantiated among many other studies comparing self-perceptions of weight with objective measurements of obesity [11, 28-30]. The kappa statistic is commonly used to measure agreement between two or more observers. A kappa statistic of 1 indicates perfect agreement between the two observers, while a kappa statistic of 0 indicates that agreement could have been due to chance [31]. Weighted kappa statistics weigh further discordant categories more heavily than closer ones. Percentage agreement and kappa statistics were also estimated to measure agreement between body fat with BMI and between self-perceptions of weight and BMI.

\section{Quantifying the associations between body fat over time with both self-perceptions of weight and underestimation of weight status}

A random effects model was employed to quantify the association of body fat over time with self-perceived weight category at baseline. Random effects regression models are often used for clustered or longitudinal data. Equation 1 lays out the model. The outcome variable, body fat as measured by BIA, is a continuous variable. The explanatory variable, self-perceptions of weight, is a categorical variable; its reference category is normal weight. The model includes an age variable that is centered at 35 years (i.e., 35 was subtracted from each age data point), which serves as a continuous variable representing time. Covariates (i.e. potential confounders) are represented as $\lambda$; these include age at baseline, sex, 
socioeconomic status, setting, and education level. Both crude and adjusted models were used.

Equation 2 lays out the model for the third objective of the study: to quantify the association between body fat over time and whether or not a participant underestimated his or her baseline weight status. Though it is similar to Eq. 1, Eq. 2 contains an explanatory variable that reflects whether or not a participant underestimated his or her weight status at baseline. This component of the study focused on individuals who underestimated their weight but were objectively overweight or obese. Thus, individuals who underestimated their weight status but were objectively normal were excluded from this analysis.

Robust standard errors were specified for both equations. Data were cleaned to address discrepancies in these variables, and a list-wise method was used to drop observations missing in the majority of variables of interest. Twelve percent of the original data from 3619 participants were therefore removed because they were missing variables. Data analysis was conducted using Stata 14 (StataCorp, TX, US).

$$
\begin{aligned}
{\left[B I A_{t}\right]=} & \beta_{0}+\beta_{1}[S P W]+\beta_{2}[\text { centered_age }] \\
& +\beta_{3}[S P W * \text { centered_age }]+\beta_{4}[\lambda]
\end{aligned}
$$

$$
\begin{aligned}
{\left[B I A_{t}\right]=} & \beta_{0}+\beta_{1}[\text { underestimate }] \\
& +\beta_{2}[\text { centered_age }] \\
& +\beta_{3}[\text { underestimate } * \text { centered_age }] \\
& +\beta_{4}[\lambda]
\end{aligned}
$$

\section{Results}

\section{General characteristics}

Table 1 displays characteristics of the 3181 participants in the study according to their BIA weight status. While $55.3 \%$ of the participants were overweight or obese, only $4.4 \%$ of participants were underweight. The prevalence of being overweight or obese was lower among partici-

\begin{tabular}{|c|c|c|c|c|c|}
\hline & Underweight & Normal & Overweight & Obese & Total \\
\hline & $n(\%)$ & $n(\%)$ & $n(\%)$ & $n(\%)$ & $n$ \\
\hline Total & $141(4.4 \%)$ & $1280(40.2 \%)$ & 1111 (34.9\%) & 649 (20.4\%) & 3181 \\
\hline \multicolumn{6}{|l|}{ Age } \\
\hline $35-44$ & 11 (1.4\%) & 267 (34.5\%) & 295 (38.1\%) & 202 (26.1\%) & 775 \\
\hline $45-54$ & $24(3.0 \%)$ & 287 (35.3\%) & 322 (39.6\%) & $181(22.2 \%)$ & 814 \\
\hline $55-64$ & $31(3.8 \%)$ & 316 (39.2\%) & 279 (34.6\%) & 181 (22.4\%) & 807 \\
\hline $65+$ & 75 (9.6\%) & 410 (52.2\%) & 215 (27.4\%) & $85(10.8 \%)$ & 785 \\
\hline \multicolumn{6}{|l|}{ Sex } \\
\hline Female & $122(7.4 \%)$ & 647 (39.5\%) & 555 (33.9\%) & 315 (19.2\%) & 1639 \\
\hline Male & 19 (1.2\%) & 633 (41.1\%) & $556(36.1 \%)$ & 334 (21.7\%) & 1542 \\
\hline \multicolumn{6}{|l|}{ Setting } \\
\hline Lima & $26(2.5 \%)$ & 384 (37.1\%) & 399 (38.6\%) & 225 (21.8\%) & 1034 \\
\hline Urban Puno & $18(3.2 \%)$ & 185 (33.3\%) & 198 (35.7\%) & 154 (27.8\%) & 555 \\
\hline Rural Puno & 70 (12.4\%) & 320 (56.6\%) & $130(23.0 \%)$ & 45 (8.0\%) & 565 \\
\hline Tumbes & $27(2.6 \%)$ & 391 (38.1\%) & $384(37.4 \%)$ & 225 (21.9\%) & 1027 \\
\hline \multicolumn{6}{|l|}{ Assets } \\
\hline Lowest & $94(9.3 \%)$ & 506 (49.9\%) & $282(27.8 \%)$ & $132(13.0 \%)$ & 1014 \\
\hline Middle & $26(2.4 \%)$ & 427 (39.8\%) & $404(37.6 \%)$ & 217 (20.2\%) & 1074 \\
\hline Highest & $21(1.9 \%)$ & 347 (31.8\%) & 425 (38.9\%) & $300(27.5 \%)$ & 1093 \\
\hline \multicolumn{6}{|l|}{ Education level } \\
\hline$<7$ years & $111(7.6 \%)$ & $678(46.6 \%)$ & $454(31.2 \%)$ & $213(14.6 \%)$ & 1456 \\
\hline $7-11$ years & $21(2.0 \%)$ & $382(36.8 \%)$ & 396 (38.1\%) & 240 (23.1\%) & 1039 \\
\hline $12+$ years & $9(1.3 \%)$ & 219 (32.0\%) & 261 (38.2\%) & 195 (28.5\%) & 684 \\
\hline
\end{tabular}
pants who were 65-years-old or older. Among the four settings, rural Puno had the lowest rates of overweight and obese weight statuses at $31.0 \%$ of its 565 participants, compared to $63.5 \%$ in urban Puno. Across the

Table 1 Demographic characteristics of the study population by weight status as body fat measured by BIA

Note: Percentages are presented across rows, such that the total of a row equals $100 \%$ 
entire study population, there were lower proportions of overweight and obese individuals in the group with lowest socioeconomic status $(40.8 \%)$ compared to the middle $(57.8 \%)$ and highest groups (66.4\%). Similarly, there were lower proportions of overweight and obese among individuals with less than 7 years of education (45.8\%) compared to those with seven to 11 years (61.2\%) and 12 or more years of education (66.7\%).

\section{Weight status agreement and weight underestimation}

Table 2 shows results of the analysis measuring agreement between self-perceptions of weight and BIA weight status in terms of percentage agreement and kappa statistics. At baseline, a total of $43.2 \%$ of the study population perceived their weight to be in a category that agreed with their BIA measured weight. This translates to a kappa statistic of 0.16. Across the four residential settings at baseline, percentage agreement and kappa statistics were highest in Tumbes $(46.5 \%$ and 0.19 , respectively) and lowest in Rural Puno (37.2\% and 0.08). Weighted agreement and kappa statistics were highest in Lima $(80.5 \%$ and 0.30$)$ and Tumbes $(79.7 \%$ and 0.31$)$ and lowest in Rural Puno (75.8\% and 0.20).

While $43.2 \%$ of participants' self-perceived weight agreed with their BIA weight status, $49.9 \%$ underestimated and $6.9 \%$ overestimated their weight status. Among the 1371 participants whose self-perceptions of weight agreed with their BIA weight status, 98 (7.1\%) were underweight, 745 (54.3\%) were normal, 510 (37.1\%) were overweight, and 20 (1.5\%) were obese. The proportion of those who underestimated their weight status ranged from $43.7 \%$ to $56.8 \%$ across the four residential settings. Among those who underestimated, 540 participants, representing $17.0 \%$ of all study participants, perceived their weight to be normal while their BIA weight status was overweight. Figure 1 displays bar graphs depicting the comparison of self-perceptions of weight status and BIA weight status, showing agreement, underestimation, and overestimation of weight across the four residential settings. Participants who perceived their weight to be obese tended to be objectively obese. In rural Puno, no participants perceived their weight to be obese, though some were objectively categorized as obese from their BIA weight status.

In terms of agreement between self-perceptions of weight and BMI, $33.1 \%$ of participants had accurate self-perceptions of their weight status. In contrast, $65.7 \%$ of participants underestimated their weight status in comparison to BMI. In terms of the two objective measurements of weight status, $62.8 \%$ of participants had BMI and BIA measurements that fell into the same weight category. Meanwhile, 30.9\% of participants were placed in a higher weight status by BMI than by BIA measurement.

\section{Association of self-perceptions of weight and body fat}

Table 3 shows the association between self-perceptions of weight and body fat over time. The crude model shows that participants who perceived themselves to be underweight had, on average, $3.1(p<0.001)$ less body fat percentage points than participants who perceived their weight to be normal. In contrast, participants who perceived themselves to be overweight or obese had, on average, $7.2(p<0.001)$ and $10.7(p<0.001)$ more body fat percentage points than participants who perceived their weight to be normal, respectively. As age increased, participants gained $0.05(p<0.001)$ body fat percentage points each year. The increase in body fat percentage points was not statistically significant across categories of self-perceived weight. After adjusting for age, sex, residential setting, socioeconomic status, and education level, results show that participants gained 0.03 $(p<0.01)$ percentage points of body fat each year.

\section{Association of underestimation and body fat}

Table 4 shows the association between underestimation of one's weight and body fat over time. Crude models show that those who underestimated their weight category tended to have $0.7 \quad(p>0.05)$ more body fat percentage points than those who correctly estimated or overestimated their weight status. However, this finding was not statistically significant. Adjustment for age, sex,

Table 2 Agreement, underestimation, overestimation, and kappa statistics of self-perceptions of weight compared to body fat as measured by bioelectric impedance (BIA) across residential settings at baseline

\begin{tabular}{|c|c|c|c|c|c|}
\hline & $\begin{array}{l}\text { Total } \\
n=3181\end{array}$ & $\begin{array}{l}\text { Lima } \\
n=1034\end{array}$ & $\begin{array}{l}\text { Urban Puno } \\
n=555\end{array}$ & $\begin{array}{l}\text { Rural Puno } \\
n=565\end{array}$ & $\begin{array}{l}\text { Tumbes } \\
n=1027\end{array}$ \\
\hline Agreement & $43.20 \%$ & $46.30 \%$ & $37.30 \%$ & $37.20 \%$ & $46.50 \%$ \\
\hline Underestimation & $49.90 \%$ & $43.70 \%$ & $56.80 \%$ & $55.80 \%$ & $49.30 \%$ \\
\hline Overestimation & $6.90 \%$ & $10.00 \%$ & $6.00 \%$ & $7.10 \%$ & $4.30 \%$ \\
\hline Kappa $(95 \%$ Cl) & $0.16(0.14-0.19)$ & $0.18(0.14-0.22)$ & $0.10(0.05-0.16)$ & $0.08(0.02-0.13)$ & $0.19(0.15-0.23)$ \\
\hline Weighted agreement & $78.70 \%$ & $80.50 \%$ & $76.50 \%$ & $75.80 \%$ & $79.70 \%$ \\
\hline Weighted kappa (95\% Cl) & $0.31(0.29-0.33)$ & $0.30(0.27-0.34)$ & $0.27(0.23-0.31)$ & $0.20(0.15-0.25)$ & $0.31(0.27-0.34)$ \\
\hline
\end{tabular}

Note: Confidence intervals for kappa coefficients were estimated using a bootstrap methodology of 1000 replications 


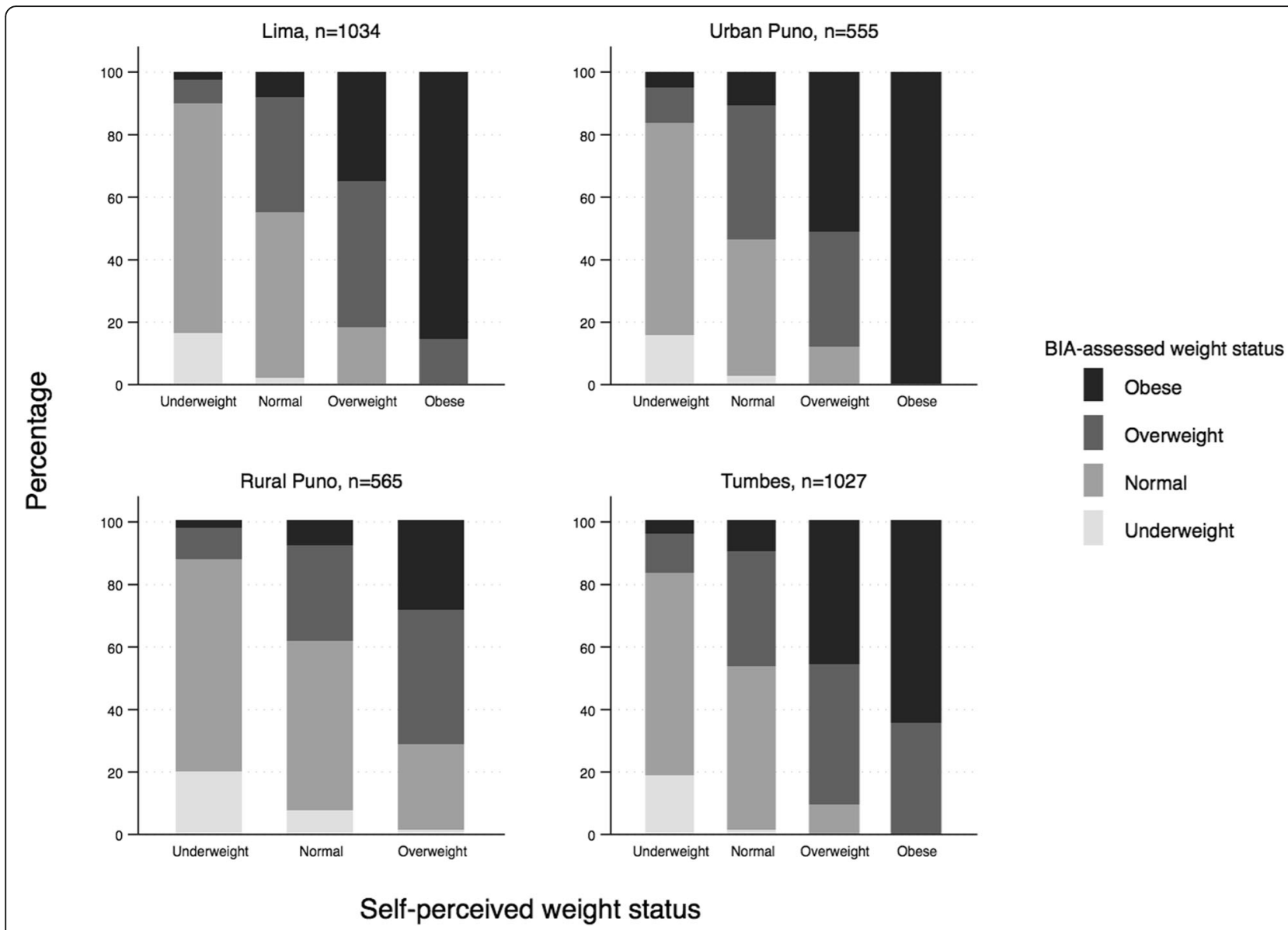

Fig. 1 Self-perceptions of weight vs. body fat as measured by bioelectric impedance (BIA) across residential setting Note: No participants in Rural Puno self-perceived to be obese. Each of the four panels reports a different residential setting in Peru. For each setting, four bars represent the four different self-perceptions of weight groups. The stacks within the bars represent the percentage breakdown of objective weight status assessed by bioelectric impedance analysis (BIA) within each self-perception of weight group

Table 3 Association of baseline self-perceptions of weight on body fat over time

\begin{tabular}{|c|c|c|c|c|}
\hline & \multicolumn{2}{|c|}{ Crude Model } & \multicolumn{2}{|c|}{ Adjusted Model } \\
\hline & Coefficient & $95 \% \mathrm{Cl}$ & Coefficient & $95 \% \mathrm{Cl}$ \\
\hline \multicolumn{5}{|l|}{ Self-perceptions of weight } \\
\hline Underweight & $-3.114^{* * *}$ & $-4.61,-1.62$ & $-4.132^{* * *}$ & $-5.29,-2.97$ \\
\hline Overweight & $7.212^{* * *}$ & $6.19,8.24$ & $5.186^{* * *}$ & $4.43,5.94$ \\
\hline Obese & $10.747^{* * *}$ & $6.11,15.39$ & $8.132^{* * *}$ & $4.89,11.37$ \\
\hline Centered Age (at 35 years) & $0.053^{* * *}$ & $0.02,0.08$ & $0.031^{* *}$ & $0.01,0.05$ \\
\hline Underweight * Centered Age & -0.011 & $-0.07,0.04$ & -0.011 & $-0.06,0.03$ \\
\hline Overweight * Centered Age & 0.03 & $-0.01,0.07$ & 0.031 & $0.00,0.06$ \\
\hline Obese * Centered Age & 0.179 & $-0.13,0.49$ & 0.182 & $-0.02,0.39$ \\
\hline Constant & $27.223^{* * *}$ & $26.51,27.94$ & $22.303^{* * *}$ & $21.46,23.15$ \\
\hline
\end{tabular}

${ }^{*} p<0.05,{ }^{* *} p<0.01$, ${ }^{* * *} p<0.001$ 
Table 4 Association of baseline underestimation of weight on body fat over time as centered age

\begin{tabular}{|c|c|c|c|c|}
\hline & \multicolumn{2}{|c|}{ Crude Model } & \multicolumn{2}{|c|}{ Adjusted Model } \\
\hline & Coefficient & $95 \% \mathrm{Cl}$ & Coefficient & $95 \% \mathrm{Cl}$ \\
\hline Underestimate & 0.723 & $-0.58,2.03$ & $2.441^{* * *}$ & $1.51,3.37$ \\
\hline Centered Age & 0.017 & $-0.03,0.07$ & 0.001 & $-0.04,0.05$ \\
\hline Underestimate ${ }^{*}$ Centered Age & 0.024 & $-0.04,0.09$ & 0.04 & $-0.01,0.09$ \\
\hline Constant & $33.462^{* * *}$ & $32.41,34.51$ & $26.010^{* * *}$ & $24.89,27.13$ \\
\hline
\end{tabular}

${ }^{*} p<0.05,{ }^{* *} p<0.01,{ }^{* * *} p<0.001$

residential setting, socioeconomic status, and education level increased the effect size of the underestimation variable from $0.7(p>0.05)$ to $2.4(p<0.001)$ body fat percentage points.

\section{Discussion}

\section{Key findings}

More than half of Peruvian adults in this study are overweight and obese, consistent with previously reported prevalence rates of overweight and obesity in Peru [2]. Furthermore, self-perceptions of weight were found to poorly agree with objective measurements of weight, as measured by both BIA and BMI. Among all participants, the agreement with self-perceptions of weight was found to be $43.2 \%$ for BIA weight status and $33.1 \%$ for BMI. More than half of the study population underestimated its weight status.

While comparing BIA weight status and BMI was not the intention of this study, these findings suggest that BIA may have less stringent definitions of overweight and obesity. One explanation for these differences is that BIA weight statuses are specific to age and sex groups while BMI is not. Nevertheless, further research is needed to investigate why BMI and BIA differ in regards to their relationship with self-perceptions of weight. The two objective measurements of weight status, BMI and BIA, have greater kappa statistics and greater percentage agreement with each other, suggesting that perceptions are less closely aligned with objective measurements. Overall, these findings suggest that individuals poorly assess their own weight status when compared to either objective measurement.

Agreement between self-perceptions of weight and BIA weight status varied across residential setting. Participants that reside in both rural and urban Puno had lower agreement (37.2 and $37.3 \%$, respectively), compared to Lima and Tumbes (46.3 and 46.5\%). Further research should be conducted to understand how geographic and cultural factors may influence self-perceived weight in these communities.

Despite poor agreement between self-perceptions of weight and BIA weight status, this study found that self-perceptions of weight were closely associated with continuous measurements of body fat percentage points.
Perceiving oneself as underweight was associated with having less body fat percentage points compared to those who perceive themselves as normal, while those who perceive themselves to be overweight and obese had higher body fat. This suggests that while there is poor self awareness of one's own weight group, those with more body fat may tend to place themselves in the higher weight categories. Similarly, those with less body fat may tend to place themselves in the lower weight categories. However, this is also likely influenced by the fact that nearly half of the study participants did not underestimate their weight status.

Furthermore, this study explores the relationship between underestimating one's weight status and objective measurements of body fat over time. Crude analysis suggested no statistically significant difference in body fat between those who underestimate their weight status and those who do not. However, after controlling for age, sex, residential setting, socioeconomic status, and education level, those who underestimate their weight status tend to have 2.4 more body fat percentage points than those who do not. This suggests a positive association between weight underestimation and body fat percentage points.

\section{Comparison with literature}

Many studies have found discordance between selfperceptions of weight and objective measurements of body fat [7-13]. This study provides five major contributions to the literature on this topic. First, this study focuses on BIA, rather than BMI, as an objective measurement of body fat. Second, this study is set in Peru. While there are several studies about obesity in the United States and Europe, there are limited studies in settings like Peru, an upper middle-income country with great socioeconomic heterogeneity and a wide diversity of geographies. Third, it utilizes a longitudinal analysis to explore the trajectory of participants' fat statuses over time given their baseline self-perception of weight. This type of analysis results in less variation across the outcome variables, because there are multiple observations for each participant. For example, this study found that, on average, participants gained just 0.03 body fat percentage points each year and such 
increase was not statistically significant across categories of self-perceived weight. Fourth, this study quantifies the association between underestimating one's weight and body fat percentage points. Past research in Peru has shown that an individual's income, education, sex, and area of residence can influence the risk of being overweight [32]. While this study controlled for age, sex, income, and education, these factors were not the focus of this study. They should be further explored to understand the determinants of discordance between selfperception of weight and objective weight measurements. A final benefit of this study is its ability to capture the natural discrepancy between self-perceived weight and objective measurements of weight. Therefore, no efforts were made to modify the understanding or education of participants, as the intent of this study was not to evaluate the intervention of health education on self-perceptions of weight. Similarly, no efforts were made to modify the usual behavior of participants, as the intent of this study was not to distort how often participants weighed themselves. As a result, it is not certain if participants had a sense of their weight at the time of this study.

\section{Public health and clinical implications}

This study shows that the majority of participants perceive themselves to belong to a weight group that differs from their objective weight group. Prior research indicate that this discordance may begin early in life and continue into adulthood, suggesting the possibility of long-term maintenance of discordant patterns of selfperceptions of weight [33]. According to the Transtheoretical Model and Precaution Adoption Process Model, behavior change takes place across six stages: pre-contemplation, contemplation, preparation, action, maintenance, and termination [34, 35]. Recognition of one's weight is a critical stage in behavior change. Incorrectly assessing one's weight may preclude healthy behaviors, such as improving one's diet or engaging in physical activity, both of which have positive effects on weight and health in general [36]. In addition, the Social-Cognitive Theory is often applied in interventions targeting weight management and physical activity. The Social-Cognitive Theory states that individuals must utilize their self-efficacy, or resiliency, to understand and overcome the barriers to making changes and meeting their goals [37]. Further research is required to ascertain the clinical significance of using self-perception of weight to facilitate lifestyle modifications. For example, it would be worthwhile to investigate if asking about self-perception of weight during clinical encounters can help improve physician-patient communication and understanding about one's weight. This may help improve weight management goals by aligning an individual's perceptions with the reality of his or her weight status. While this study shows that underestimating one's weight status may be associated with having more body fat, after controlling for demographic and socioeconomic characteristics, future research is needed to definitively understand the factors that influence an individual's likelihood of improperly self-perceiving their weight status, as well as the factors that would motivate behavior change. Further research is also needed to assess if clinicians and public health practitioners would benefit from tailoring interventions according to self-perceptions of weight status, underestimating one's weight status, or BIA.

\section{Limitations}

This study has several limitations. First, the residential sites in the study included four areas that are not representative of all of Peru. Nevertheless, the sites provide a heterogeneity of settings that vary in environmental characteristics, making these results more generalizable than a study conducted at a single site. Secondly, the measurement of BIA body fat percentage points is calculated using an algorithm from TBF-300A that is proprietary to the manufacturer. While the robustness of TBF-300A results has been demonstrated in past published studies [17-20], there is no substitute for having a complete understanding of equations used to calculate BIA estimates. Still, any potential measurement error is assumed to be constant across the whole study population. In addition, BIA measurements themselves have several limitations. BIA measurements may vary depending upon several factors including consumption of food and drink, proximity of time since physical activity, temperature, and menstrual cycles [15]. These factors were not controlled for in the study and therefore may distort BIA findings. Finally, the categorization of weight status using Gallagher's classifications may not adequately represent the Peruvian population. The original study to obtain these classifications was performed in the United Kingdom, United States, and Japan on white, African American, and Asian individuals [22]. The intention of this study was not to establish a set of new definitions of body status, but instead to utilize a mechanism to compare self-perception of weight and actual weight status. Future research to develop robust, standardized definitions of weight status using body fat is critical to linking biological and behavioral characteristics in the study of obesity.

\section{Conclusion}

Among Peruvian adults, poor agreement between self-perceptions of weight and objective measurements of body fat using BIA was found. Longitudinal regression analysis reveals that participants in this study gained an 
average of 0.03 body fat percentage points each year. More than half of participants in the study underestimated their weight. After adjusting for sex, age, socioeconomic status, education and residential setting, underestimation of weight status was associated with having a greater percentage of body fat compared to not underestimating one's weight. Future research should explore the characteristics that influence an individual to underestimate his or her weight status. Further research should also investigate how using self-perceptions of weight can impact lifestyle modifications and behavior change in clinical and public health settings.

\section{Abbreviations}

BIA: Bioelectric impedance analysis; BMI: Body mass index

\section{Acknowledgements}

We would like to thank Rodrigo M. Carrillo-Larco and Alvaro Taype-Rondan for their guidance during initial conceptualizing of this project, as well as

Victoria F. Bachman for her support with copyediting

\section{Funding}

This project was funded in whole with Federal funds from the United States National Heart, Lung, and Blood Institute, National Institutes of Health, Department of Health and Human Services, under Contract No. HHSN268200900033C. ALB was further supported by the UCLA Blum Center on Poverty and Health in Latin America. WC was further supported by a Pathway to Independence Award (ROOHL096955) from the National Heart, Lung and Blood Institute. LS was a Senior Clinical Fellow and ABO a Research Training Fellow in Public Health and Tropical Medicine (103994/Z/ 14/Z), both funded by Wellcome Trust. JJM acknowledges receiving additional support from the Alliance for Health Policy and Systems Research (HQHSR1206660), DFID/MRC/Wellcome Global Health Trials (MR/M007405/1), Fogarty International Center (R21TW009982, D71TW010877), Grand Challenges Canada (0335-04), International Development Research Center Canada (106887, 108167), Inter-American Institute for Global Change Research (IAI CRN3036), Medical Research Council (MR/P008984/1, MR/P024408/ 1, MR/P02386X/1), National Cancer Institute (1P20CA217231), National Heart Lung and Blood Institute (HHSN268200900033C, 5U01HL114180, 1UM1HL134590), National Institute of Mental Health (1U19MH098780), Swis National Science Foundation (40P740-160366), Wellcome Trust (074833/Z/ 04/Z, 093541/Z/10/Z, 107435/Z/15/Z, 103994/Z/14/Z, 205177/Z/16/Z) and the World Diabetes Foundation (WDF15-1224).

\section{Availability of data and materials}

The datasets generated and/or analyzed during the current study are available from the corresponding author on reasonable request.

\section{Authors' contributions \\ JJM had full access to all the data in the study and takes responsibility for the integrity of the data and the accuracy of the data analysis. Study concept and design: ALB, ABO, JJM. Acquisition, analysis, and interpretation of the data: All authors. Drafting of the manuscript: ALB, MGM, ABO, JJM. Critical revision of the manuscript for important intellectual content: All authors. Statistical analysis: ALB, MGM, ABO. Obtained funding: ALB, JJM. Administrative, technical, and material support: ALB, ABO, JJM. Study supervision: $\mathrm{ABO}, \mathrm{JJM}$. All authors have read and approved the final version of the manuscript.}

\section{Ethics approval and consent to participate}

This study was conducted according to the guidelines laid down in the Declaration of Helsinki and all procedures involving human subjects of the CRONICAS Cohort Study were approved by the institutional review boards of the Universidad Peruana Cayetano Heredia, the Asociación Benéfica PRISMA in Lima, Peru, and the Johns Hopkins University in Baltimore, USA. Written informed consent was obtained from all subjects.
Consent for publication

Not applicable.

\section{Competing interests}

The authors declare that they have no competing interests.

\section{Publisher's Note}

Springer Nature remains neutral with regard to jurisdictional claims in published maps and institutional affiliations.

\section{Author details}

'David Geffen School of Medicine at UCLA, Los Angeles, CA, USA. ${ }^{2}$ CRONICAS Centre of Excellence in Chronic Diseases, Universidad Peruana Cayetano Heredia, Av. Armendáriz 497, Miraflores, Lima 18, Peru. ${ }^{3}$ School of Public Health and Administration, Universidad Peruana Cayetano Heredia, Lima, Peru. ${ }^{4}$ Department of International Health, Bloomberg School of Public Health, Johns Hopkins University, Baltimore, MD, USA. ${ }^{5}$ Faculty of Epidemiology and Population Health, London School of Hygiene and Tropical Medicine, London, UK. ${ }^{6}$ School of Medicine, Universidad Peruana Cayetano Heredia, Lima, Peru.

Received: 13 April 2018 Accepted: 10 January 2019 Published online: 01 April 2019

References

1. Trends in adult body-mass index in 200 countries from 1975 to 2014: a pooled analysis of 1698 population-based measurement studies with 19.2 million participants. Lancet [Internet]. 2016 Apr [cited 2016 Dec 30]; 387(10026):1377-96. Available from: http://linkinghub.elsevier.com/retrieve/ pii/S014067361630054X

2. Institute for Health Metrics and Evaluation (IHME). Overweight and Obesity Viz [Internet]. IHME, University of Washington. 2014 [cited 2016 Jul 13]. Available from: http://www.healthdata.org/results/country-profiles

3. Atlantis E, Ball K. Association between weight perception and psychological distress. Int J Obes. 2008;32(4):715-21 [cited 2016 Jul 13]. Available from: http://www.nature.com/doifinder/10.1038/sj.ijo.0803762.

4. Cash TF, Hicks KL. Being fat versus thinking fat: relationships with body image, eating behaviors, and well-being 1. Cognit Ther Res. 1990;14(3):327-41.

5. Xie B, Chou C-P, Spruijt-Metz D, Reynolds K, Clark F, Palmer PH, et al. Weight perception and weight-related sociocultural and behavioral factors in Chinese adolescents. Prev Med (Baltim). 2006;42(3):229-34

6. Forman MR, Trowbridge FL, Gentry EM, Marks JS, Hogelin GC. Overweight adults in the United States: the behavioral risk factor surveys. Am J Clin Nutr. 1986;44(3):410-6 [cited 2016 Jul 13]. Available from: https://academic. oup.com/ajcn/article-abstract/44/3/410/4691992

7. Johnson-Taylor WL, Fisher RA, Hubbard VS, Starke-Reed P, Eggers PS, Ogden $C$, et al. The change in weight perception of weight status among the overweight: comparison of NHANES III (1988-1994) and 1999-2004 NHANES. Int J Behav Nutr Phys Act. 2008;5(1):9 [cited 2016 Jul 13] Available from: http://ijbnpa.biomedcentral.com/articles/10.1186/1479-5868-5-9.

8. Kuchler F, Variyam JN. Mistakes were made: misperception as a barrier to reducing overweight. Int J Obes. 2003;27(7):856-61 [cited 2016 Jul 13]. Available from: http://www.nature.com/doifinder/10.1038/s.i.jo.0802293.

9. Fitzgibbon ML, Blackman LR, Avellone ME. The relationship between body image discrepancy and body mass index across ethnic groups. Obes Res. 2000;8(8):582-9 [cited 2016 Jul 13]. Available from: http://doi.wiley.com/10. 1038/oby.2000.75

10. Paeratakul S, White MA, Williamson DA, Ryan DH, Bray GA. Sex, race/ ethnicity, socioeconomic status, and BMI in relation to self-perception of overweight. Obes Res. 2002;10(5):345-50 [cited 2016 Jul 13]. Available from: http://doi.wiley.com/10.1038/oby.2002.48.

11. Loret de Mola C, Pillay TD, Diez-Canseco F, Gilman RH, Smeeth L, Miranda $J$, et al. Body mass index and self-perception of overweight and obesity in rural, urban and rural-to-urban migrants: PERU MIGRANT study. PLoS One. 2012:7(11):e50252 O'Rourke D, editor. [cited 2016 Jul 13]. Available from: http://dx.plos.org/10.1371/journal.pone.0050252.

12. Chang WW, Christakis NA, Mokdad AH, Bowman BA, Ford ES, Vinicor F, et al. Self-perception of weight appropriateness in the United States. Am J Prev Med. 2003:24(4):332-9 [cited 2016 Jul 13]. Available from: http://linkinghub. elsevier.com/retrieve/pii/S0749379703000205. 
13. Brener ND, Eaton DK, Lowry R, McManus T. The association between weight perception and BMI among high school students. Obes Res. 2004;12(11): 1866-74 [cited 2016 Jul 13]. Available from: http://doi.wiley.com/10.1038/ oby.2004.232

14. Shuster A, Patlas M, Pinthus JH, Mourtzakis M. The clinical importance of visceral adiposity: a critical review of methods for visceral adipose tissue analysis. https://www.birpublications.org/doi/full/10.1259/bjr/38447238. 2014;

15. Dehghan M, Merchant AT, Dentali F, Sharma A, Douketis J, Merchant A, et al. Is bioelectrical impedance accurate for use in large epidemiological studies? Nutr J. 2008;7(1):26 [cited 2016 Jul 13]. Available from: http:// nutritionj.biomedcentral.com/articles/10.1186/1475-2891-7-26.

16. Miranda JJ, Bernabe-Ortiz A, Smeeth L, Gilman RH, Checkley W, CRONICAS Cohort Study Group CCS. Addressing geographical variation in the progression of non-communicable diseases in Peru: the CRONICAS cohort study protocol. BMJ Open. 2012;2(1):e000610 [cited 2016 Jul 13]. Available from: https://bmjopen.bmj.com/content/2/1/e000610.long.

17. Terbizan D, Rhee Y, Stasny S. A comparison of body composition techniques. Missouri J Heal Phys Educ Recreat Danc. 2009;19:104-11.

18. Andreacci JL, Nagle T, Fitzgerald E, Rawson ES, Dixon CB. Effect of Exercise Intensity on Percent Body Fat Determined by Leg-to-Leg and Segmental Bioelectrical Impedance Analyses in Adults. http://dx.doi.org/101080/ 027013672013762314. 2013;

19. Kapidzic A, Hasukic S, Mehinovic J, Atikovic A, Nozinovic Mujanovic A, Mujanovic E. Body mass index and volume of fat tissue of unemployed men in the Tuzla Canton Índice de Masa corporal y Volúmen de Tejido Graso en hombres Desempleados de Tuzla Canton. Int J Morphol. 2015; 33(1):158-63.

20. Vazquez-Vidal I, Chittoor G, Laston S, Puppala S, Kayani Z, Mody K, et al. Assessment of cardiovascular disease risk factors in a genetically homogenous population of Parsi Zoroastrians in the United States: a pilot study. Am J Hum Biol. 2016;28(3):440-3 [cited 2016 Jul 13]. Available from: http://doi.wiley.com/10.1002/ajhb.22834.

21. TANITA. Tanita Technology Explained: Bioelectric Impedance ANalysis [Internet]. [cited 2016 Jul 13]. Available from: http://tanita.eu/tanitaacademy/tanita-technology-explained

22. Gallagher D, Heymsfield SB, Heo M, Jebb SA, Murgatroyd PR, Sakamoto Y. Healthy percentage body fat ranges: an approach for developing guidelines based on body mass index. Am J Clin Nutr. 2000;72(3):694-701 [cited 2016 Jul 13]. Available from: https:/academic.oup.com/ajcn/article/72/3/694/4729363.

23. Jahanlou AS, Kouzekanani K. The accuracy of body mass index and Gallagher's classification in detecting obesity among Iranians. Iran J Med Sci. 2016;41(4):288-95 [cited 2016 Jul 14]. Available from: http://ijms.sums.ac.ir/ index.php/IJMS/article/view/1253.

24. Pasco JA, Holloway KL, Dobbins AG, Kotowicz MA, Williams $\sqcup$, Brennan SL. Body mass index and measures of body fat for defining obesity and underweight: a cross-sectional, population-based study. BMC Obes. 2014;1:9 [cited 2016 Jul 14]. Available from: https://bmcobes.biomedcentral.com/articles/10.1186/2052-9538-1-9.

25. Pasco JA, Nicholson GC, Brennan SL, Kotowicz MA. Prevalence of obesity and the relationship between the body mass index and body fat: crosssectional, population-based data. PLoS One. 2012;7(1):e29580 Wang G, editor [cited 2016 Jul 14]. Available from: http://dx.plos.org/10.1371/journal. pone.0029580

26. National Institutes of Health. Clinical guidelines on the identification, evaluation, and treatment of overweight and obesity in adults--the evidence report. National Institutes of Health. Obes Res. 1998:6(Suppl 2):51S-209S [cited 2017 May 29]. Available from: https:/www.healthypeople.gov/2020/tools-resources/ evidence-based-resource/clinical-guidelines-on-the-identification-evaluation

27. Howe LD, Galobardes B, Matijasevich A, Gordon D, Johnston D, Onwujekwe $\mathrm{O}$, et al. Measuring socio-economic position for epidemiological studies in low- and middle-income countries: a methods of measurement in epidemiology paper. Int J Epidemiol. 2012;41(3):871-86 [cited 2017 Dec 19]. Available from: https://academic.oup.com/ije/article/41/3/871/833303.

28. Sutcliffe CG, Schultz K, Brannock JM, Giardiello FM, Platz EA. Do people know whether they are overweight? Concordance of self-reported, interviewer-observed, and measured body size. Cancer Causes Control. 2015;26(1):91-8 [cited 2016 Jul 13]. Available from: http://link.springer.com/ 10.1007/s10552-014-0487-y.

29. Chang EY, Kim JS, Shin SJ. Health promotion lifestyle according to selfperception of obesity and objective status measured by bioelectric impedance analysis in college women. J Korean Acad Nurs. 2009;39(5):693-
9 [cited 2016 Jul 13]. Available from: https://www.jkan.or.kr/DOlx.php?id=10. 4040/jkan.2009.39.5.693.

30. Wang Y, Liang H, Chen X, Ogden C, Carroll M, Curtin L, et al. Measured body mass index, body weight perception, dissatisfaction and control practices in urban, low-income African American adolescents. BMC Public Health. 2009;9(1):183 [cited 2016 Jul 20]. Available from: http:// bmcpublichealth.biomedcentral.com/articles/10.1186/1471-2458-9-183.

31. Viera AJ, Garrett JM. Understanding interobserver agreement: the kappa statistic. Fam Med. 2005;37(5):360-3.

32. Jacoby E, Goldstein J, López A, Núñez E, López T. Social class, family, and life-style factors associated with overweight and obesity among adults in Peruvian cities. Prev Med (Baltim). 2003;37(5):396-405.

33. Black JA, Park M, Gregson J, Falconer CL, White B, Kessel AS, et al. Child obesity cut-offs as derived from parental perceptions: cross-sectional questionnaire. Br J Gen Pract. 2015;65(633):e234-9 [cited 2017 Jan 27]. Available from: https://bjgp.org/content/65/633/e234.long.

34. Prochaska JO, Velicer WF. The Transtheoretical model of health behavior change. Am J Health Promot. 1997;12(1):38-48 [cited 2016 Aug 24]. Available from: http://ajhpcontents.org/doi/abs/10.4278/0890-1171-12.1.38.

35. Weinstein ND, Rothman AJ, Sutton SR. Stage theories of health behavior: conceptual and methodological issues. Health Psychol. 1998;17(3):290-9 [cited 2016 Aug 24]. Available from: http://www.ncbi.nlm.nih.gov/pubmed/ 9619480.

36. Brug J, Wammes B, Kremers S, Giskes K, Oenema A. Underestimation and overestimation of personal weight status: associations with sociodemographic characteristics and weight maintenance intentions. J Hum Nutr Diet. 2006;19(4)253-62 [cited 2016 Aug 24]. Available from: https:// onlinelibrary.wiley.com/doi/abs/10.1111/j.1365-277X.2006.00707.X.

37. Palmeira AL, Teixeira PJ, Branco TL, Martins SS, Minderico CS, Barata JT, et al. Predicting short-term weight loss using four leading health behavior change theories. Int J Behav Nutr Phys Act. 2007:4(1):14 [cited 2017 Dec 20]. Available from: http://ijbnpa.biomedcentral.com/articles/10.1186/1479-5868-4-14.

Ready to submit your research? Choose BMC and benefit from:

- fast, convenient online submission

- thorough peer review by experienced researchers in your field

- rapid publication on acceptance

- support for research data, including large and complex data types

- gold Open Access which fosters wider collaboration and increased citations

- maximum visibility for your research: over $100 \mathrm{M}$ website views per year

At $\mathrm{BMC}$, research is always in progress.

Learn more biomedcentral.com/submissions 